\title{
The pattern of neonatal gastro-intestinal perforation in upper Egypt
}

\author{
Nezar Abd Elrouf Abo-Halawa ${ }^{1 *}\left(\mathbb{D}\right.$, Mohamed Ahmed Negm ${ }^{1}$ a and Mohamed Fathy ${ }^{2}$
}

\begin{abstract}
Background: Neonatal gastro-intestinal perforation [NGIP] is one of the major problems in pediatric surgical practice. Although the outcomes of neonatal surgery have improved markedly over the past decade the mortality rates of neonates with NGIP are still high. The aim of this study was to present the possible etiological factors, clinical findings, and operative procedures of NIP in our locality.

Results: A total of 34 neonates with NGIP were included in this study. The median age at presentation was (15.8 \pm $7.0 \mathrm{SD}$ ) days. The median interval between presentation and surgical interference was (2.0 $\pm 1.1 \mathrm{SD}$ ). Necrotizing enterocolitis [NEC] was the commonest cause of neonatal gastro-intestinal perforation. The commonest site of perforation was the colon [11cases]. The overall mortality rate was 11 cases [32.4\%]. The main cause of mortality was neonatal NEC [6 cases]. Eight cases [40\%] died out of 20 cases which the interval between the presentation and interference were more than one day.

Conclusions: Neonatal gastro-intestinal perforations are still associated with high mortality rate in our institutions, and delayed diagnosis with increased interval between the presentation and surgical intervention are associated with increased mortality. In our locality, although NEC is the commonest cause of NGIP, the iatrogenic cause is relatively higher than reported.
\end{abstract}

Keywords: Neonatal gastro-intestinal perforation, Necrotizing enterocolitis, Perforation, Upper Egypt

\section{Background}

Neonatal gastro-intestinal perforation [NGIP] is one of the major problems facing pediatric surgeons worldwide [1]. Necrotizing enterocolitis [NEC] is still the major cause of NIP [2]. Although the outcomes of neonatal surgery have been improved markedly over the past decade due to the development of neonatal intensive management and care, as ventilator care, better surgical, and anesthetic techniques such as ventilator management, operative, and anesthetic techniques, the mortality rates of neonates with NIP are still high, ranging from 15 to $70 \%$. This mortality depends on some causes such as birth weight, number of perforation, and delayed

\footnotetext{
* Correspondence: drnezar1@med.svu.edu.eg

${ }^{1}$ Pediatric Surgery unit, Qena Faculty of Medicine, South Valley University,

Qena, Egypt

Full list of author information is available at the end of the article
}

presentation [3-10]. However, early diagnosis and rapid transfer of these cases may have a good prognostic value.

The aim of this study was to present our experience of NGIP as the possible etiological factors, clinical findings and operative procedures in our locality at Upper Egypt. We also sought to investigate the relationship between the demographic characteristics data [gestational age, birth weight, the age of presentation and sex] as well as operative findings (causes of NGIP, sites, numbers of perforation and operative procedures done) with prognosis and survival rate of NIP. The identification of this relationship may enable early intervention, possibly leading to improved outcomes.

\section{Methods}

After institutional review board approval, a retrospective review of all neonates with NGIP at Upper Egypt from

\section{Springer Open}

(c) The Author(s). 2020 Open Access This article is licensed under a Creative Commons Attribution 4.0 International License, which permits use, sharing, adaptation, distribution and reproduction in any medium or format, as long as you give appropriate credit to the original author(s) and the source, provide a link to the Creative Commons licence, and indicate if changes were made. The images or other third party material in this article are included in the article's Creative Commons licence, unless indicated otherwise in a credit line to the material. If material is not included in the article's Creative Commons licence and your intended use is not permitted by statutory regulation or exceeds the permitted use, you will need to obtain permission directly from the copyright holder. To view a copy of this licence, visit http://creativecommons.org/licenses/by/4.0/. 
October 2014 to April 2017 was performed. Data were collected from patient's charts including age, sex, gestational age, birth weight, age at presentation, clinical features on examination, interval between presentation and intervention, radiological finding (plain X-rays, contrast studies and ultrasound study), laboratory findings, causes and sites of perforations, types of operative procedures, and mortality and morbidity.

\section{Results}

A total of 43 patients were managed during the period under review but 9 cases were excluded due to incomplete data. Thirty-four (34) neonates with neonatal gastro-intestinal perforation were included in this study. There were 19 male $(55.9 \%)$ and 15 female (44.1\%).

\section{Age}

The average age at presentation was $15.8 \pm 7.0$ days, with a range of 3-28 days. Their birth weight ranged from 1500 to $3600 \mathrm{~g}$. Gestational age of the subjects ranged from 30 to 40 weeks with an average of $36.03 \pm$ 2.736. The presentation-surgical intervention interval was 1-6 days (SD 2.0 \pm 1.1 ) (Table 1).

\section{Diagnosis of NGIP}

Fifteen cases (44.1\%) were diagnosed clinically and radiologically (plain abdominal X-rays and/or contrast study), 13 cases (38.2 \%) were diagnosed by radiological studies, 5 cases $(14.7 \%)$ were diagnosed by clinical examination with inconclusive radiological studies while one case was discovered during laparotomy done for exomphalos minor.

\section{Causation}

In this study, necrotizing enterocolitis was the commonest cause of neonatal gastro-intestinal perforation with16 cases, followed by 6 iatrogenic perforations. Hirschsprung's disease (HSD) was the cause of NGIP in 5 cases; 3 of them were iatrogenic while 2 were spontaneous. Neglected jejunoileal atresia resulted in NIP in 2 cases while one case was classified idiopathic. One case each resulted from complicated meconium peritonitis, Meckel's diverticulum, neglected anorectal malformation and Exomphalos minor with perforated Meckel's diverticulum (Fig. 1, Table 2) The causes of the 6 iatrogenic perforations were; rectal perforation after contrast enema in 2 cases (Fig. 2), rectal perforation after colonic washout in another 2 cases and gastric perforation after nasogastric tube insertion in 2 cases.

The site of perforation was found in the colon in 11 cases followed by ileum in 8 cases, rectum in 5 cases (Fig. 3), stomach in 3 cases, jejunum in only one case (Fig. 4). Multiple perforations involving the ileum and colon were seen in 3 cases, the stomach and colon in 2 cases while it involved stomach and ileum in one case (Table 3).

\section{Treatment}

The main line of treatment in this study was creation of a stoma. Colostomy was performed in 12 cases and ileostomy in 11 cases. Primary closure was performed in 6 patients; 3 in the stomach, 1 in the ileum, and 2 in the small bowel. Small bowel resection and anastomosis was done in only three cases while two cases were treated with primary peritoneal drainage. One of these patients died while the later underwent successful primary closure (Table 4).

Table 1 Patients' demographic and clinical data

\begin{tabular}{|c|c|c|}
\hline Demographics & Range & Mean \pm SD \\
\hline \multicolumn{3}{|l|}{ Gender } \\
\hline - Male & $20(58.8 \%)$ & \\
\hline - Female & $14(41.2 \%)$ & \\
\hline Gestational age (weeks) & $30-40$ & $36.03 \pm 2.736$ \\
\hline Age at presentation (days) & $3-28$ & $15.79 \pm 7.023$ \\
\hline Weight (grams) & $1500-3400$ & $2541.18 \pm 492.438$ \\
\hline The interval between presentation and interference (days) & $1-6$ & $1.97 \pm 1.141$ \\
\hline \multicolumn{3}{|l|}{ The interval between presentation and interference (day) } \\
\hline - 1day & $13(38.2 \%)$ & \\
\hline -2days & $14(41.3 \%)$ & \\
\hline$\cdot 3$ days & $5(14.7 \%)$ & \\
\hline - 5 days & $1(2.9 \%)$ & \\
\hline - 6 days & $1(2.9 \%)$ & \\
\hline
\end{tabular}




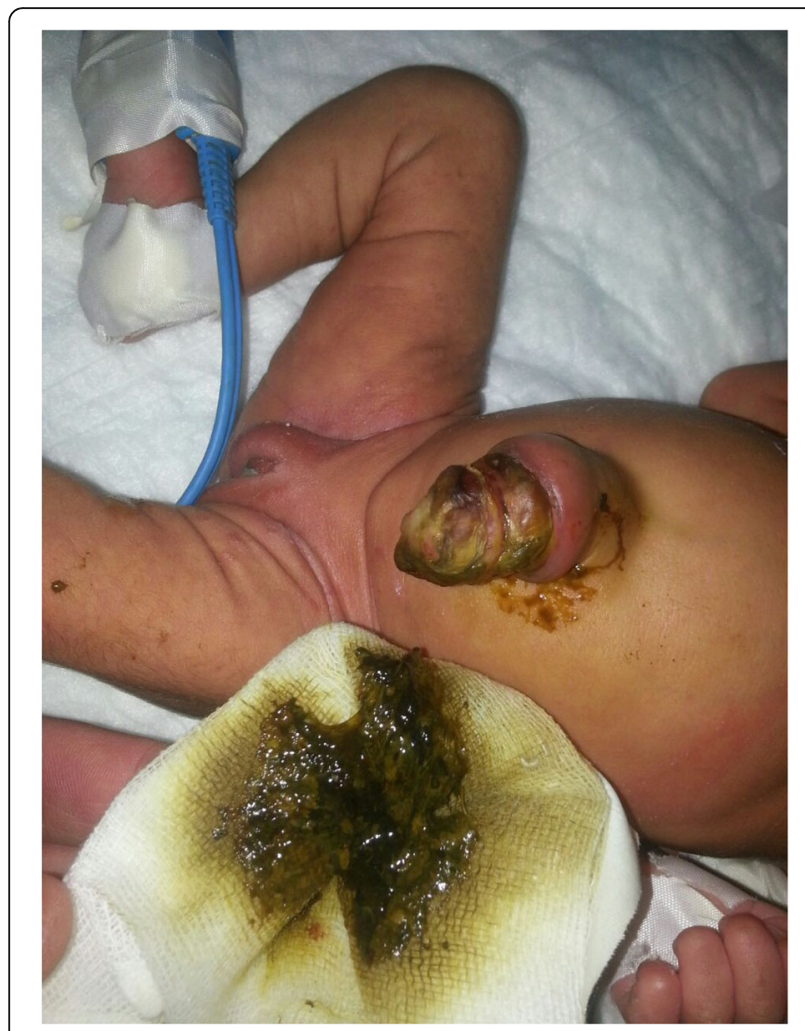

Fig. 1 Exomphalos with perforated Meckel's diverticulum

\section{Post-operative complications}

Surgical site infection was recorded in 19 cases (55.9\%), followed by sepsis in 16 (47.1\%). Malnutrition occurred in 9 cases $(26.5 \%)$ patients, skin excoriation in 6 cases (17.6\%) and anastomotic leakage in 2 cases (5.9\%). All dead 11 patients had postoperative sepsis. Five of these cases had sepsis with malnutrition, 4 had sepsis alone, 1 case had sepsis, malnutrition, and leakage with burst abdomen while in 1 case, and there was sepsis with anastomotic leakage.

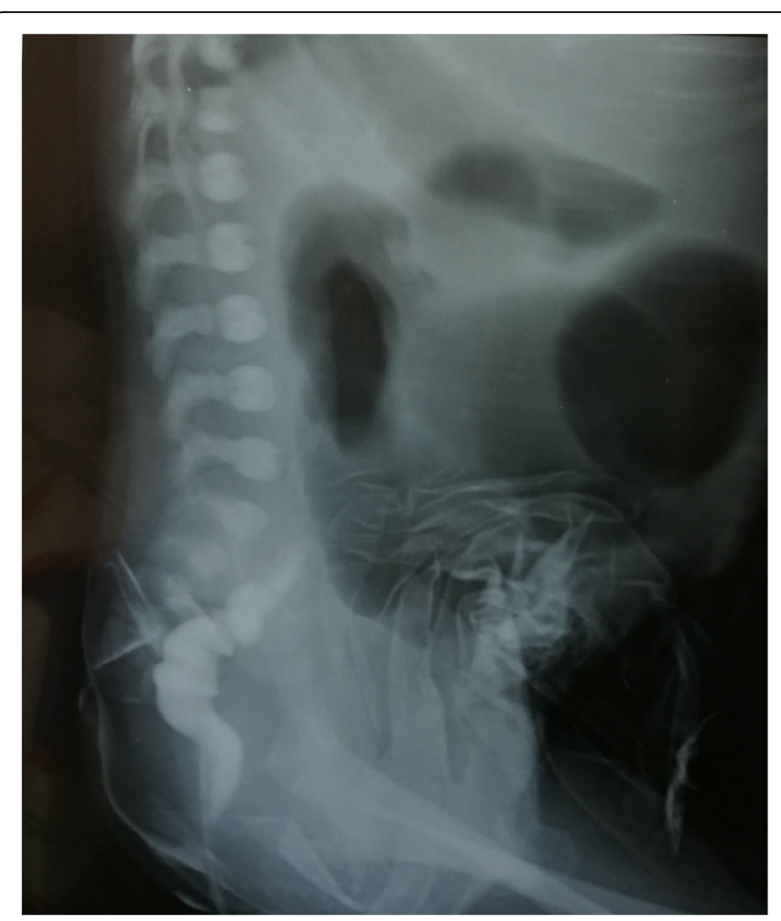

Fig. 2 Gastrographin enema show rectal perforation with extravasation of contrast in the peritoneal cavity

\section{Mortality}

The overall mortality rate was 11 cases $(32.4 \%)$. The main causes of mortality were NEC [ 6 cases], jejunoileal atresia [2 cases], ARM [1 case], rectal injury [1 case], and meconium peritonitis [1 case].

\section{Gestational age (Table 5)}

Out of 10 cases with low birth weight (1500-2500 gm), 7 cases $(70 \%)$ died. The only case of a very low birth weight $(1300 \mathrm{gm})$ also died. However, only 3 babies $(13 \%)$ of 23 babies with birth weight $>2500$ gm died.

Table 2 Cause-related prognosis of gastro-intestinal perforations

\begin{tabular}{|c|c|c|c|c|c|c|}
\hline \multirow[t]{2}{*}{ Cause } & \multicolumn{2}{|c|}{$\underline{\text { Survival }}$} & \multicolumn{2}{|c|}{ Mortality } & \multicolumn{2}{|c|}{ Total } \\
\hline & $\bar{N}$ & $\%$ & $N$ & $\%$ & $N$ & $\%$ \\
\hline NEC & 10 & 29.4 & 6 & 17.6 & 16 & 47.1 \\
\hline latrogenic perforation & 5 & 17.6 & 1 & 2.9 & 7 & 20.6 \\
\hline HSD & 5 & 11.8 & 0 & 0 & 4 & 11.8 \\
\hline Exomphalos with perforated Meckel's diverticulum & 1 & 2.9 & 0 & 0 & 1 & 2.9 \\
\hline High ARM without fistula & 0 & 0 & 1 & 2.9 & 1 & 2.9 \\
\hline Ileal atresia & 0 & 0 & 1 & 2.9 & 1 & 2.9 \\
\hline Jejunal atresia & 0 & 0 & 1 & 2.9 & 1 & 2.9 \\
\hline Meconium ileus with perforation & 0 & 0 & 1 & 2.9 & 1 & 2.9 \\
\hline Idiopathic gastric perforation & 1 & 2.9 & 0 & 0 & 1 & 2.9 \\
\hline Volvulus & 1 & 2.9 & 0 & 0 & 1 & 2.9 \\
\hline Total & 23 & 67.6 & 11 & 32.4 & 34 & 100 \\
\hline
\end{tabular}




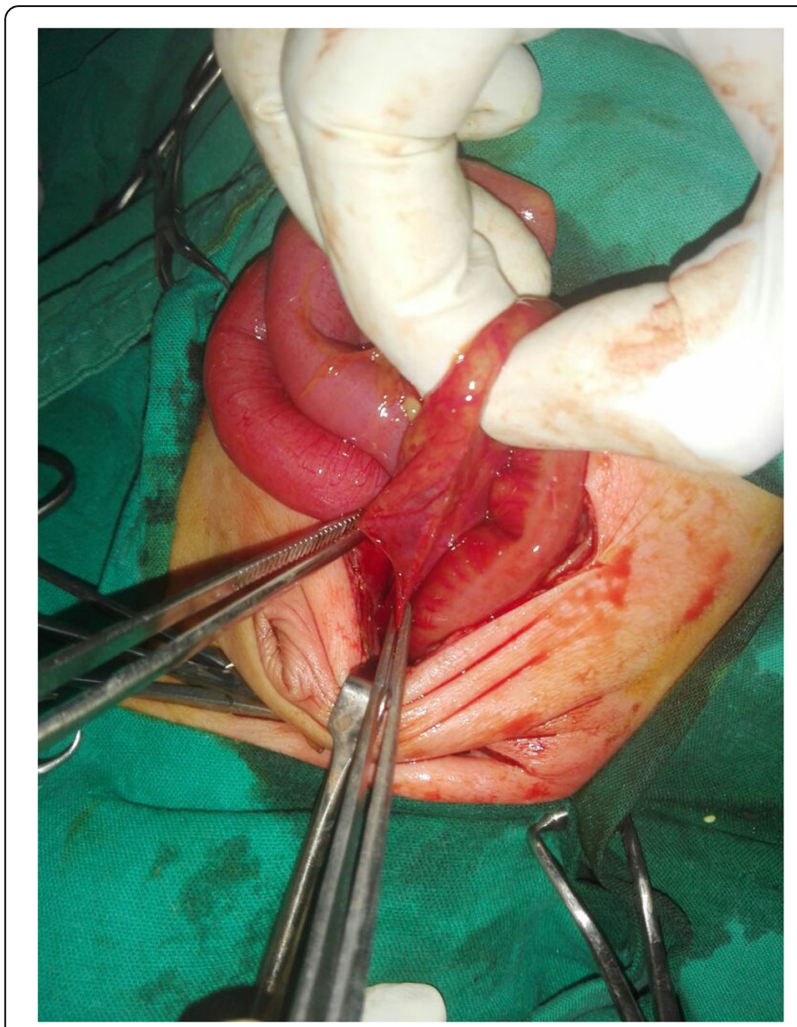

Fig. 3 Anterior wall rectal perforation

Prematurity was therefore strongly correlated with death $(P$ value $=0.002)$.

\section{Age of presentation}

Of 9 cases who presented at age 10 days or less, 4 cases (44.4\%) died with -ve correlation ( $P$ value 0.06 ) while out of 25 cases with age at presentation more than 10 days, 7 cases (28\%) cases died (Table 5), the difference was not statistically significant.

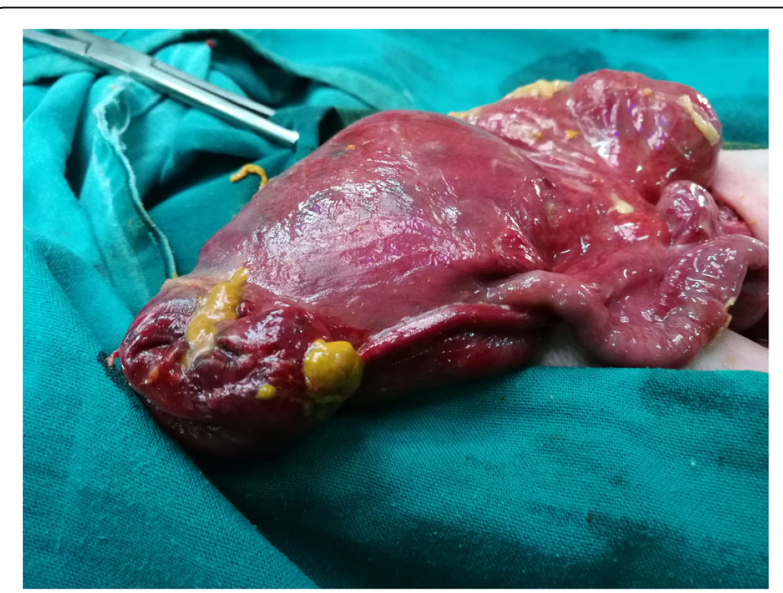

Fig. 4 Jejunal perforation with jejunal atresia
Table 3 Sites related prognosis of gastro-intestinal perforations

\begin{tabular}{|c|c|c|c|c|c|c|}
\hline \multirow[t]{2}{*}{ Causes } & \multicolumn{2}{|c|}{ Survival } & \multicolumn{2}{|c|}{ Mortality } & \multicolumn{2}{|c|}{ Total } \\
\hline & $\bar{N}$ & $\%$ & $\bar{N}$ & $\%$ & $\bar{N}$ & $\%$ \\
\hline Gastric & 2 & 5.9 & 1 & 2.9 & 3 & 8.8 \\
\hline Jejunum & 0 & 0 & 1 & 2.9 & 1 & 2.9 \\
\hline Stomach and colon & 1 & 2.9 & 1 & 2.9 & 2 & 5.9 \\
\hline Stomach and ileum & 0 & 0 & 1 & 2.9 & 1 & 2.9 \\
\hline Ileum & 6 & 17.6 & 1 & 2.9 & 7 & 20.6 \\
\hline Ileum and colon & 1 & 2.9 & 2 & 5.9 & 3 & 8.8 \\
\hline Meckel & 1 & 2.9 & 0 & 0.0 & 1 & 2.9 \\
\hline Colonic & 9 & 26.5 & 2 & 5.9 & 11 & 32.4 \\
\hline Rectum & 3 & 8.8 & 2 & 5.9 & 5 & 14.7 \\
\hline Total & 23 & 67.6 & 11 & 32.4 & 34 & 100 \\
\hline
\end{tabular}

\section{Presentation-intervention interval}

Twenty cases had surgical intervention more than 1 day. Eight cases (40\%) of these patients died. Only 3 cases (27.3\%) of 11 babies who presented within $24 \mathrm{~h}$ died. Intervention time of more than 1 day was significantly associated with high mortality rate $(P$ value $=0.016)$.

\section{No of perforations}

Multiple perforations were strongly associated with high mortality rate in this study $(P$ value $=0.01)($ Table 6$)$.

\section{Discussion}

Early identification of infants with NGIP may lead to prompt treatment with sure benefit to the outcome. All surgical neonatal emergencies depend mainly on the efficacy of the bases of surgical care which was provided by hospitals and surgeons. It has been known for some time that the level and volume of neonatal intensive care at the hospital of birth strongly influences mortality rate of neonates in need of surgical intervention [11-14].

Proper referral and transportation also had its impact on the chances of neonate's prognosis following emergency surgery [15]. This fact is very important in our locality as only two centers have adequate facilities for neonatal surgical intervention for NGIP. The results of

Table 4 Surgical intervention and outcomes

\begin{tabular}{|c|c|c|c|c|c|c|}
\hline \multirow[t]{2}{*}{ Operative procedure } & \multicolumn{2}{|c|}{ Survival } & \multicolumn{2}{|c|}{ Mortality } & \multicolumn{2}{|c|}{ Total } \\
\hline & $\bar{N}$ & $\%$ & $\bar{N}$ & $\%$ & $\bar{N}$ & $\%$ \\
\hline Colostomy & 8 & 23.5 & 4 & 11.9 & 12 & 35.3 \\
\hline Ileostomy & 10 & 29.5 & 1 & 2.9 & 11 & 32.4 \\
\hline Primary closure & 3 & 8.8 & 3 & 8.8 & 6 & 17.6 \\
\hline Resection and anastomosis & 1 & 2.9 & 2 & 5.9 & 3 & 8.8 \\
\hline primary peritoneal drainage & 1 & 2.9 & 1 & 2.9 & 2 & 5.9 \\
\hline Total & 23 & 67.6 & 11 & 32.4 & 34 & 100 \\
\hline
\end{tabular}


Table 5 The relationship between the demographic characteristics and prognosis

\begin{tabular}{|c|c|c|c|c|}
\hline Demographics & $\begin{array}{l}\text { Survived } \\
N(\%) \\
23(100 \%)\end{array}$ & $\begin{array}{l}\text { Died } \\
N(\%) \\
11(100 \%)\end{array}$ & $\begin{array}{l}\text { Total } \\
N(\%) \\
34(100 \%)\end{array}$ & $P$-value \\
\hline \multicolumn{5}{|l|}{ Gender } \\
\hline Male & 14 (60.9\%) & $6(54.5 \%)$ & $20(58.8 \%)$ & \multirow[t]{2}{*}{0.7} \\
\hline Female & 9 (39.1\%) & $5(45.5 \%)$ & $14(41.2 \%)$ & \\
\hline \multicolumn{5}{|l|}{ Gestational age } \\
\hline Preterm & 9 (39.1\%) & $8(72.7 \%)$ & $17(50 \%)$ & \multirow[t]{2}{*}{0.002} \\
\hline Full term & 14 (60.9\%) & $3(27.3 \%)$ & $17(50 \%)$ & \\
\hline \multicolumn{5}{|l|}{ Age at presentation } \\
\hline 10 days or less & $4(17.4 \%)$ & $4(36.4 \%)$ & $8(23.5 \%)$ & \multirow[t]{2}{*}{0.06} \\
\hline More than 10 days & 19 (82.6\%) & $7(63.6 \%)$ & $26(76.5 \%)$ & \\
\hline \multicolumn{5}{|l|}{ Weight } \\
\hline Low birth weight & $3(13 \%)$ & $7(63.6 \%)$ & $10(41.2 \%)$ & \multirow[t]{2}{*}{$\leq 0.001$} \\
\hline Normal birth Wight & $20(87 \%)$ & $4(36.4 \%)$ & $24(58.8 \%)$ & \\
\hline \multicolumn{5}{|c|}{$\begin{array}{l}\text { The interval between presentation } \\
\text { and intervention }\end{array}$} \\
\hline Less than 1 day & $11(47.8 \%)$ & $3(27.3 \%)$ & $14(41.2 \%)$ & \multirow[t]{2}{*}{0.016} \\
\hline More than 1 day & $12(52.2 \%)$ & $8(72.7 \%)$ & $20(58.8 \%)$ & \\
\hline
\end{tabular}

this study showed that delayed diagnosis and transfer are of the most important causes of increased mortality. In the same way, the increased interval between the presentation and intervention may lead to high mortality rate.

This may be attributed to lack of clinical experience for early diagnosis, lack of communication between pediatricians and pediatric surgeons, in addition to delay in transfer of babies after diagnosis to our institutions. This mandates continuous communication between pediatricians and pediatric surgeons to improve clinical experience, early diagnosis, and management. Moreover, good training is required for paramedical and nursing staff dealing with neonates.

In cases with NEC, pneumoperitoneum is the most relevant radiological indicator of bowel perforation that may need surgical intervention. However, pneumoperitoneum is present in less than half of all infants with gastro-intestinal perforation or necrosis at the time of operative exploration [16]. In our study, five cases were diagnosed by clinical examination with inconclusive

Table 6 Study outcome according to the number of perforations

\begin{tabular}{|c|c|c|c|c|c|c|c|}
\hline \multirow{2}{*}{$\begin{array}{l}\text { Number of } \\
\text { perforation }\end{array}$} & \multicolumn{2}{|c|}{ Survived } & \multicolumn{2}{|c|}{ Died } & \multicolumn{2}{|c|}{ Total } & \multirow{2}{*}{$\begin{array}{l}P \\
\text { value }\end{array}$} \\
\hline & $\bar{N}$ & $\%$ & $N$ & $\%$ & $\bar{N}$ & $\%$ & \\
\hline 1 & 22 & 64.7 & 6 & 17.6 & 28 & 82.4 & 0.01 \\
\hline 2 & 1 & 2.9 & 3 & 8.8 & 4 & 11.8 & \\
\hline Multiple & 0 & 0 & 2 & 5.9 & 2 & 5.9 & \\
\hline Total & 23 & 67.6 & 11 & 32.4 & 34 & 100 & \\
\hline
\end{tabular}

radiological studies, also two cases of died from NEC, the radiological $\mathrm{X}$-ray is insignificant, and transport of babies was delayed, so it is important to increase the clinical sense and raise suspicion and other diagnostic modalities for diagnosis of perforation in NEC.

It is reported that necrotizing enterocolitis is the most devastating and frequent surgical emergency in the neonatal intensive care units (NICUs), occurring in 0.7 per 1000 patients, and in up to $7 \%$ of those hospitalized in NICU. An estimated 20 to $40 \%$ of infants with NEC will need surgical interference, and the mortality rate in these infants can be as high as 50\% [17-20]. In our study, NEC is the commonest cause of death [54.5\%] with high incidence in preterm cases, which is similar to other studies [9, 21]. In the current study, necrotizing enterocolitis is the commonest cause of NGIP (47.1\%), which is similar to those reported by others $[1,4,6$, 21-23].

According to the result of this study, there are relatively high percentage of the iatrogenic perforation (sex cases), and most of the cases were caused by inexperienced staff during contrast enema or rectal wash, which indicate the need of adequate training and good supervision to decrease these causes, this is similar to result detect by Elhalaby et al. who reported also a relatively high frequency of iatrogenic colorectal perforations [1].

In the present study, the prognosis was better in large bowel perforation more than small bowel perforation, and this is similar to other studies [21-23]. This result can correlate with line of treatment as the prognosis is better in neonate underwent colostomy rather than 
other line of treatment especially ileostomy and resection with anastomosis. This finding can be explained by the fact that colostomy reduces the time of surgery, and early postoperative feeding which is important in our institutes due to lack of availability of total parental nutrition.

Mortality from NGIP is still high, although advancements in anesthesia and neonatal intensive care, the high mortality has to increase extremely premature babies $[7$, 24]. In this study, mortality rate is high in prematurity, low birth weight, multiple perforations, and delayed presentation which was similar to what reported by other authors $[1,4,6,8,12,21,23]$.

\section{Conclusion}

Neonatal gastro-intestinal perforations are still associated with high mortality rate in our institutions, delayed diagnosis with increased interval between the presentation and surgical intervention are associated with increased mortality. In our locality, although NEC is the commonest cause of NGIP, the iatrogenic cause is relatively higher than reported.

\section{Abbreviations}

NGIP: Neonatal gastro-intestinal perforation; NEC: Necrotizing enterocolitis; HSD: Hirschsprung's disease; ARM: Anorectal malformations

\section{Acknowledgements}

Not applicable

\section{Authors' contributions}

N. A. and M.F. gave idea and collected the patients' data and data analysis. M.N. put study design. N. A. and M.N wrote and revised the paper. N.A., M.N., and M. F. performed all surgery. They all read and approved the final version of the manuscript.

\section{Funding}

This study had no funding from any resource

\section{Availability of data and materials}

The datasets used and/or analyzed during the current study are available from the corresponding author on reasonable request.

\section{Ethics approval and consent to participate}

This study was approved by the Research Ethics Committee of the Faculty of Medicine at South Valley University in Qena, Egypt on 30 September 2014; Reference Number of approval is F36. Written informed consent of all patients for their participation was given by their parent or legal guardian.

\section{Consent for publication}

All parents of patients included in this research gave written informed consent to publish the data contained within this study.

\section{Competing interests}

The authors declare that they have no competing interests.

\section{Author details}

${ }^{1}$ Pediatric Surgery unit, Qena Faculty of Medicine, South Valley University, Qena, Egypt. ${ }^{2}$ Pediatric Surgery Unit, Faculty of Medicine, Minia University, Minia, Egypt.
Received: 30 October 2019 Accepted: 15 May 2020

Published online: 25 June 2020

\section{References}

1. Elhalaby EA, Elsamongy AF, Eldesoky NI, Dawoud HH, Darwish AA, Atia MA, et al. Neonatal gastrointestinal perforations. Egypt. J. Surg. 2000;19(2):78-86.

2. Komuro H, Urita Y, Hori T, Hirai M, Kudou S, Gotoh C, et al. Perforation of the colon in neonates. Journal of pediatric surgery. 2005;40(12):1916-9.

3. Sato M, Hamada Y, Kohno M, Ise K, Uchida K, Ogata H, et al. Neonatal gastrointestinal perforation in Japan: a nationwide survey. Pediatric surgery international. 2017:33(1):33-41.

4. Eltayeb AA, Hashem M. Management and outcome of neonatal bowel perforation. Ann Pediatr Surg. 2008:4:83-8.

5. Fares AE, El-Saket HM. Neonatal colonic perforation: a case series. Arab Gastroenterol. 2008;9(3):75-9.

6. Chirdan $L B$, Ameh EA. Neonatal intestinal perforation in a developing country. Annals of tropical paediatrics. 2001;21(1):26-8.

7. Fujii AM, Brown E, Mirochnick M, O'Brien S, Kaufman G. Neonatal necrotizing enterocolitis with intestinal perforation in extremely premature infants receiving early indomethacin treatment for patent ductus arteriosus. Journal of perinatology. 2002;22(7):535-40.

8. Asabe K, Oka Y, Kai H, Shirakusa T. Neonatal gastrointestinal perforation. The Turkish journal of pediatrics. 2009;51(3):264.

9. Emil S, Davis K, Ahmad I, Strauss A. Factors associated with definitive peritoneal drainage for spontaneous intestinal perforation in extremely low birth weight neonates. European journal of pediatric surgery. 2008:18(02):80-5.

10. St-Vil D, LeBouthillier G, Luks Fl, Bensoussan A, Blanchard H, Youssef S. Neonatal gastrointestinal perforations. Journal of pediatric surgery. 1992;27(10):1340-2.

11. Stark AR. American Academy of Pediatrics Committee on F, Newborn. Levels of neonatal care. Pediatrics. 2004;114:1341-7.

12. Phibbs CS, Baker LC, Caughey AB, Danielsen B, Schmitt SK, Phibbs RH. Level and volume of neonatal intensive care and mortality in very-low-birthweight infants. New England Journal of Medicine. 2007;356(21):2165-75.

13. Jensen EA, Lorch SA. Effects of a birth hospital's neonatal intensive care unit level and annual volume of very low-birth-weight infant deliveries on morbidity and mortality. JAMA pediatrics. 2015;169(8):-e151906.

14. Kastenberg ZJ, Lee HC, Profit J, Gould JB, Sylvester KG. Effect of deregionalized care on mortality in very low-birth-weight infants with necrotizing enterocolitis. JAMA Pediatr. 2015;169:26-32.

15. Kelley-Quon LI, Tseng CH, Scott A, Jen HC, Calkins KL, Shew SB. Does hospital transfer predict mortality in very low birth weight infants requiring surgery for necrotizing enterocolitis? Surgery. 2012;152:337-43.

16. Munaco AJ, Veenstra MA, Brownie E, Danielson LA, Nagappala KB, Klein MD. Timing of optimal surgical intervention for neonates with necrotizing enterocolitis. Am Surg. 2015;81:438-43.

17. Zhang Y, Ortega G, Camp M, Osen H, Chang DC, Abdullah F. Necrotizing enterocolitis requiring surgery: outcomes by intestinal location of disease in 4371 infants. Journal of pediatric surgery. 2011:46(8):1475-81.

18. de Souza JC, Fraga JC. Is mortality rate influenced by the site of involvement in neonates undergoing laparotomy for necrotizing enterocolitis? J Pediatr Surg. 2009:44:1534-9.6.

19. Feldens L1, Souza JCK2, Fraga JC3. There is an association between disease location and gestational age at birth in newborns submitted to surgery due to necrotizing enterocolitis. J Pediatr (Rio J). 2017 30. pii: S0021-7557(17)30141-9.

20. Guner, Y. S., Chokshi, N., Petrosyan, M., Upperman, J. S., Ford, H. R., \& Grikscheit, T. C. (2008, November). Necrotizing enterocolitis-bench to bedside: novel and emerging strategies. In Seminars in pediatric surgery (Vol. 17, No. 4, pp. 255-265). WB Saunders.

21. Hyginus EO, Jideoffor U, Victor M. Gastrointestinal perforation in neonates: aetiology and risk factors. Journal of neonatal surgery. 2013;2(3).

22. Haithem H. Ali Almoamin. Review of 31 cases of neonatal gastrointestinal perforations. Fac Med Baghdad. 2016; 58, No.2.

23. Tiwari C, Sandlas G, Jayaswal S, Shah H. Spontaneous intestinal perforation in neonates. Journal of neonatal surgery. 2015;4(2).

24. Rees CM, Eaton S, Kiely EM, Wade AM, McHugh K, Pierro A. Peritoneal Drainage or Laparotomy for Neonatal Bowel Perforation? A Randomized Controlled Trial. Ann Surg. 2008;248:44-51.

\section{Publisher's Note}

Springer Nature remains neutral with regard to jurisdictional claims in published maps and institutional affiliations. 